\title{
OPTIMAL BALANCING AND CONTROL OF A DYNAMIC LOAD DEMAND IN A GRID CONNECTED HYBRID SYSTEM USING FEED-IN TARIFF APPROACH
}

Master's Student, Department of Electronic System Engineering Institute of Information and Communication Technologies, Mehran UET. Jamshoro (Pakistan)

E-mail: abdullah.qazi92@gmail.com

Irfan Ahmed Halepoto

Department of Electronic Engineering, Mehran UET. Jamshoro (Pakistan)

E-mail: irfan.halepoto@gmail.com

Kamran Kazi

Department of Electronic Engineering, Mehran UET. Jamshoro (Pakistan) E-mail: kamran.kazi@faculty.muet.edu.pk

Recepción: 05/03/2019 Aceptación: 10/04/2019 Publicación: 17/05/2019

\section{Citación sugerida:}

Qazi, A., Halepoto, I. A. y Kazi, K. (2019). Optimal Balancing and Control of a Dynamic Load Demand in a Grid Connected Hybrid System using Feed-in Tariff Approach. 3C Tecnología. Glosas de innovación aplicadas a la pyme. Edición Especial, Mayo 2019, pp. 350-365. doi: http://dx.doi.org/10.17993/3ctecno.2019.specialissue2.350-365

Suggested citation:

Qazi, A., Halepoto, I. A. \& Kazi, K. (2019). Optimal Balancing and Control of a Dynamic Load Demand in a Grid Connected Hybrid System using Feed-in Tariff Approach. 3C Tecnología. Glosas de innovación aplicadas a la pyme. Special Issue, May 2019, pp. 350-365. doi: http://dx.doi.org/10.17993/3ctecno.2019.specialissue2.350-365 


\section{ABSTRACT}

In this paper, we have proposed, designed and simulated a grid connected residential smart home system benefiting from hybrid energy system (HES) for optimal balancing and control of a dynamic load using Feed-in Tariffs (FiT) tariffs by increasing the onsite self-consumption of solar PV system. To achieve the object function, two different PV system configuration scenarios were designed, simulated and analyzed for different case studies. In first scenario, PV system without battery backup storage system (BBSS) under FiT scheme with flat tariffs was investigated for a typical day of winter and summer. In second scenario, PV system with BBSS under FiT scheme with ToU tariffs was investigated again for a typical day of winter and summer. The optimal balancing and dynamic load control can be achieved by increasing the penetration level of solar PV by maximizing the onsite self-consumption of PV system, minimizing the grid electricity import in high ToU tariff periods, charging the battery during low ToU tariffs, discharging the battery during high ToU tariffs and exporting the excessive PV generation in peak PV generation periods especially in summer season. The simulated results suggest that significant revenue can be saved, and optimal balancing and control can be achieved when PV system is configured with BBSS under FiT scheme by utilizing ToU tariffs. The proposed will be more cost effective and optimal control can be achieved if implemented to residential community microgrids by using cooperative game theory approach.

\section{KEYWORDS}

Solar PV system, Battery Backup storage system, Hybrid Energy System, Feedin Tariffs, Time of Use tariffs. 


\section{INTRODUCTION}

The superfluous usage of energy resources by humans for the luxurious living standards and ever increasing industrialization and commercialization for sustainable growth have put the serious stress on energy reserves especially on non-renewable as in near past no major discovery of energy source reserves have been found around the globe (Halepoto, Uqaili \& Chowdhry, 2014). This is a gigantic concerned situation as this can limit the sustainable growth around the globe. According to world energy reports, it is anticipated that with current rate of energy resources utilization, the oil, natural gas and coal reserves will last to only for 50, 75 and 140 years for an average to the globe if no other major discovery is being made (Narula, 2019). This situation has shifted the more focus on the utilization of renewable energy resources (solar, wind) and energy conservation techniques in form of Demand Side Management (Sahito, Halepoto, Uqaili, Memon, Larik \& Mahar, 2015). As the matter of fact, this world has strong solar irradiation potential and wind belts which are being used but the penetration level needs to be increased (Sahito, Arain, Halepoto, Soomro \& Jumani, 2016). As compared to wind turbines, the solar irradiation intensity is easily available and can be utilize optimally for energy generation (Kaplan, Agalar \& Bildircin, 2019). Similarly Demand Side Management (DSM) being the promising approach is the main research area and resulting significantly to reduce, schedule, manage and optimize the energy consumption at consumer side of the power utility distribution system (Ahmed, Levorato \& Li, 2018). With DSM, the utility can introduce the price incentive in form of ToU. During high load stress periods, high on peak ToU tariffs and during low load stress, low ToU tariffs can be offered. This will mutually benefit the consumer in billing and utility grid in reducing the system stress load. If these two promising areas can be integrated in a systematic way that a grid connected HES can be developed to utilize both the renewable distributed energy resources (DERs) like solar or wind turbine when they are available naturally and at the same time in the periods when these sources are not available, then optionally utility grid can be utilized accordingly where utility can offer ToU tariffs conditionally. This will form a type 
of grid connected microgrid system, such HES will not only increase the DERs penetration level but will also reduce the stress to non-renewable resources and at the same can be cost effective and will reduce carbon emission significantly (Ju, Wang, Goel \& Xu, 2018).

In this connection a major concern is that when the conventional utility grid is to be utilize and when non-conventional DERs to be utilized. The optimal balancing and control of such HES need to be investigated especially considering the availability of DERs and DSM. In this paper we are proposing an optimal balancing and control of a dynamic load demand in a grid connected HES system (solar PV and utility grid) using DSM techniques. The PV system will be integrated with utility grid and based on requirement the load can be import and to and from utility grid and PV generation system. This will generate different scenario of utilizing the onsite PV system generation and utilization, PV to be export to grid, generated PV load to be stored in batteries, load directly utilized the utility grid based on flat and ToU tariffs prices offered by utilities.

The rest of paper is organized as under: In section 2, the proposed system under the study is presented by considering different input parameters and an object function is formulated to achieve the optimal balancing and control of dynamic load. In section 3, a PV system is configured by using two case scenarios to investigate the impact of battery storage and incentive based pricing. The work is concluded in section 4 .

\section{SYSTEM UNDER STUDY - INPUT PARAMETERS AND MODELING}

In this paper, system under study is a grid connected residential microgrid considering of a utility grid, smart meter for consumer-utility bidirectional communication and to update about the electricity pricing, solar photovoltaic (PV) system, solar PV generation meter, a BBSS, DC to AC inverter and charger, residential consumer load data profile as shown in Figure 1. The system configuration of the proposed residential home model is based on object function 
formulation, 24 hour load profile, flat and ToU tariffs, solar PV generation and feed in tariff $(\mathrm{FiT})$ data.

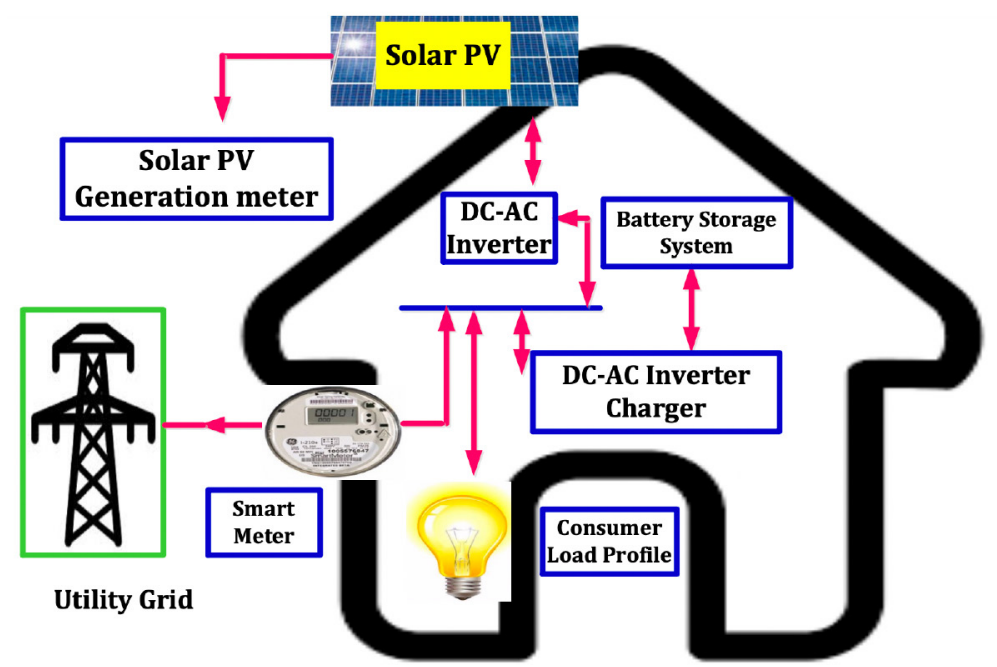

Figure 1. System under Study with Residential PV-Battery Storage Configuration.

\subsection{MATHEMATICAL OBJECT FUNCTION FORMULATION}

The two main parameters of object function are where defines the selected days of year and is the of set of one hour periods in selected days. This object function is formulated by Eq. 1 and 2. Eq. 1 maximize the solar PV self-consumption through FiT and Eq. 2 minimize the utility grid import using flat and ToU tariff cases with and without BBSS. The formulated object function is evaluated for FiT scheme, flat tariff and ToU tariffs.

$$
\begin{gathered}
\text { Object Function }=\max \sum_{\left(d_{y}, t_{h}\right)} P V\left(d_{y}, t_{h}\right) \times P V_{F i T}+P V_{\text {on site genreation }}+P V_{\text {battery charging }} \\
+P V_{\text {export }} \times \Delta t . .(1) \\
\begin{aligned}
\text { Object Function }= & \min \sum_{\left(d_{y}, t_{h}\right)} P V\left(d_{y}, t_{h}\right) \times P V_{F i T}-\text { Grid }_{\text {flat traiff }}-\text { Grid }_{\text {ToU taraiff }}-\text { Grid }_{\text {electrcity import }} \\
& - \text { Grid }_{\text {battery chrgging }} \times \Delta t . .(2)
\end{aligned}
\end{gathered}
$$




\subsection{LOAD PROFILE DATA}

The selected residential smart home load data were measured and recorded by using smart meter for 365 days. The minimum recorded load was $0.7 \mathrm{~kW}$ and the maximum recorded load was $6 \mathrm{~kW}$.

\subsection{FEED IN TARIFFS (FIT)}

The FiT tariff combines the generation and export tariffs. The generation tariffs define every $\mathrm{kWh}$ of PV generated energy being paid and the export tariff defines every kWh of energy being exported.

\subsection{FLAT TARIFFS}

Although nowadays in developed countries ToU tariffs are being implemented but in countries like Pakistan we still do have flat tariff system which is mostly are slab based tariffs. In this work, to import the electricity, flat tariffs are proposed at Rs. 12/kWh for 24-hour load on a selected day.

\subsection{TOU TARIFFS}

The load profile is very dynamic as it depends on many factors, but this variability of load profile can be managed if ToU tariffs to be during on and off peak periods in form high and low tariffs than routine tariffs. This will give an option to a consumer to get benefit of ToU to reduce electricity bill and at the same reducing utility system stress in on peak hours. This approach is mutually beneficial for both consumer and the utility. The proposed ToU tariffs are shown in Figure 2. 


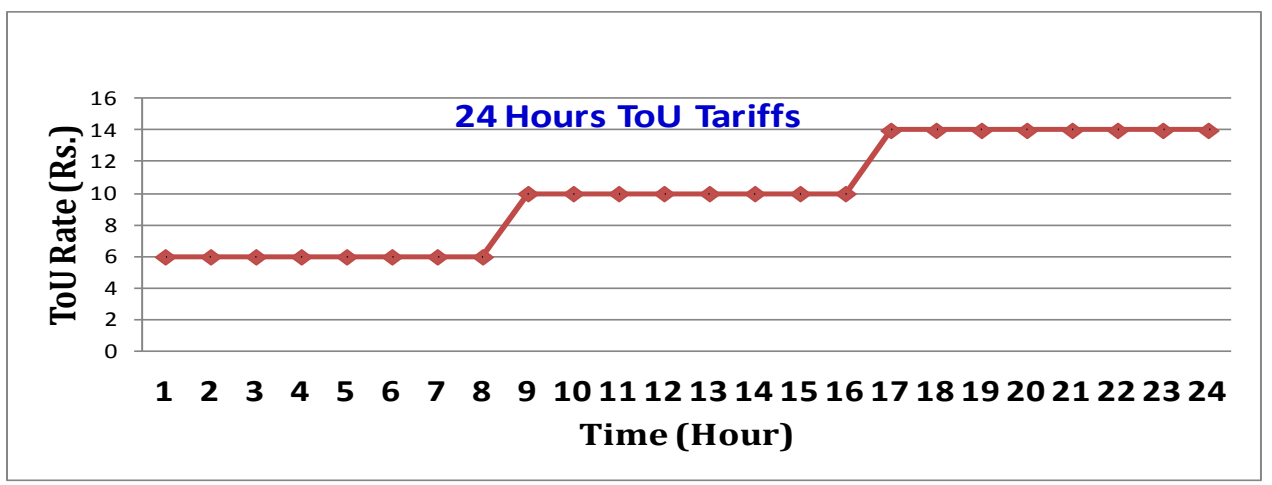

Figure 2. Proposed ToU tariffs.

Although, ToU approach is very attractive for residential consumer when utility offers off peak periods but in periods of on peak hours, the potential of solar PV can be used as an grid connected microgrid source not only to fulfill own needs in on peak periods but can export to the utility in case surplus through battery backup storage system.

\subsection{SOLAR PV GENERATION DATA AND TARIFFS}

The total installed solar PV generation capacity of the proposed system is $6.5 \mathrm{~kW}$. The PV generation data is obtained and recorded through hourly smart meter readings. The cost of PV generation is estimated by FiT scheme, where 14.5 Rs/ $\mathrm{kWh}$ is set as an import generation tariff and $7.5 \mathrm{Rs} / \mathrm{kWh}$ is finalized as export tariff.

\subsection{BATTERY BACKUP STORAGE SYSTEM}

Due to the intermittent nature of solar PV and non-linear load consumer requirements, BBSS is the potential solution to maximize the self-consumption of solar PV and to optimize the import generation tariffs and export tariffs by benefiting from the FiT scheme and ToU tariffs (Bakhshi \& Sadeh, 2018). Figure 3 shows the 24 hour load profile of a selected day illustrating the actual and average load consumption profile of test case home which confirms load unevenness. 


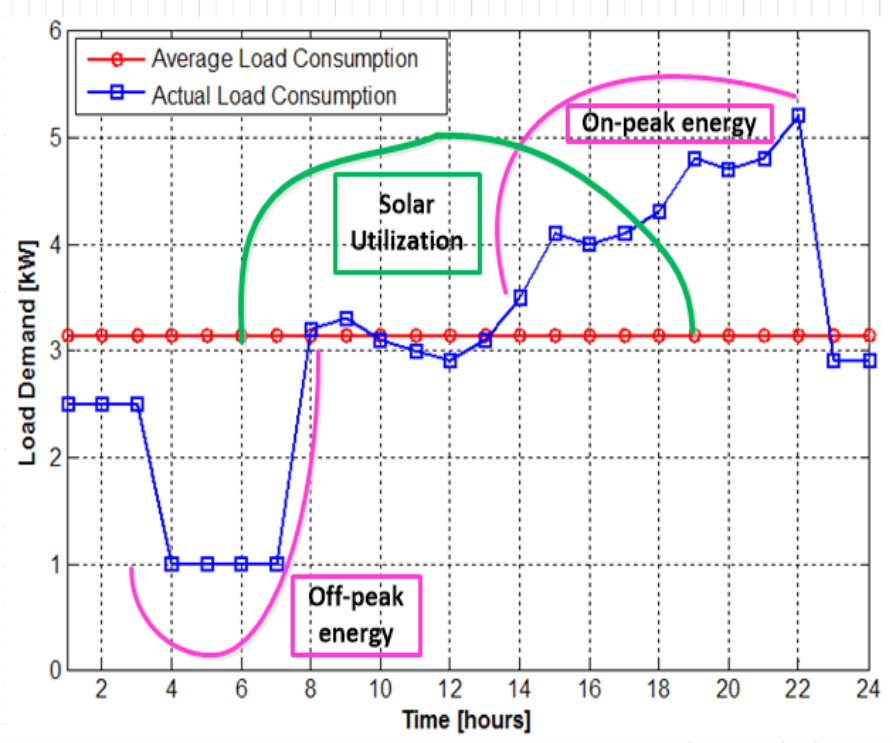

Figure 3. Solar power utilization into BBSS for energy shifting during on-off periods.

The high peak load is $5.2 \mathrm{kWh}$ at $22^{\text {nd }}$ hour of the day, while off peak load is $1 \mathrm{kWh}$ between 4 to 7 hours of the day. The average load consumption is $3.14 \mathrm{kWh}$. This graph confirms the presence of both the on peak and off peak periods. The BBSS will maximize the solar PV usage periods by storing the excess PV power during on peak hours tariff.

\section{SYSTEM DESIGN SCENARIOS: SIMULATION RESULTS AND ANALYSIS}

Two case scenarios are designed, modeled and simulated two objective functions as described in Eq. 1 and 2. Test case scenario 1 and 2 are designed, simulated and analyzed for PV System under FiT scheme without BSS at Flat Tariff and PV System under FiT scheme with BSS at ToU.

\subsection{CASE SCENARIO 1: PV SYSTEM UNDER FIT SCHEME WITHOUT BSS AT FLAT TARIFFS}

In this case scenario, as there is no battery storage system, so the smart home consumer is supposed to buy and use the grid electricity at flat tariffs set by utility 
grid. The designed PV generation system configuration without BSS for case scenario 1 is shown in Figure 4. At the utility grid side, smart meters indicate the electricity import (to be purchased from PV) and export rates (to be sell to PV consumer) through import and export meters. On the other hand, solar PV generation meter indicate the overall PV generation over the defined periods. Based on PV generation and load demand consumer decide to sell or purchase the electricity to and from utility grid. Based on object function presented in Eq. 1 and 2, system designed in Figure 4 is simulated for the 365 days of the year. To represent the seasonal cases the one day is selected from winter and summer to analyses the both the grid and PV generation, load demand and electricity import or export without BSS.

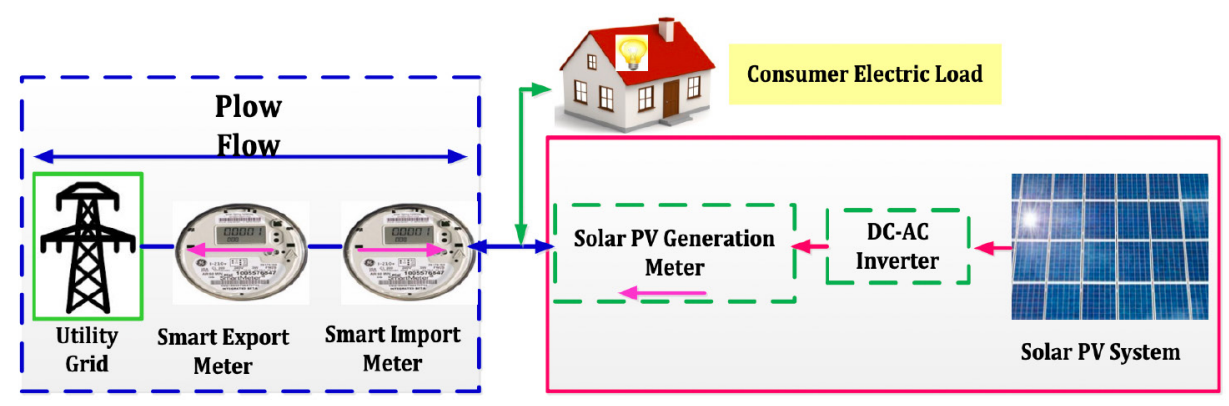

Figure 4. PV system design configuration without BSS under FiT and Flat Tariffs.

Traditionally winter season represents the low PV generation and maximum grid electricity loads due to low solar irradiance. Based on object function presented in Eq. 1, the system designed in Figure 4 is trained for the 365 days and simulated and analyzed for one selected day of the winter. On a selected day of winter, in early hours of the morning, the meet the load demand, the electricity is required to be imported from the utility, as the solar irradiance will be low. As the day progress, the solar irradiance increases so the PV generation thus electricity import from the grid decreases accordingly. Similarly PV used onsite for self-consumption and PV exported in cases when the PV generation meets and excess the load demand accordingly. These results are shown in Figure 5. During winter due to low PV generation most of power is consumed onsite and PV export is very low. On the period of day (after 17th hour) when the PV generation is not available, 
the grid electricity is imported to meet the load demand at flat tariffs defined by utility grid. This will increase the increase the cost or consumer electricity bill.

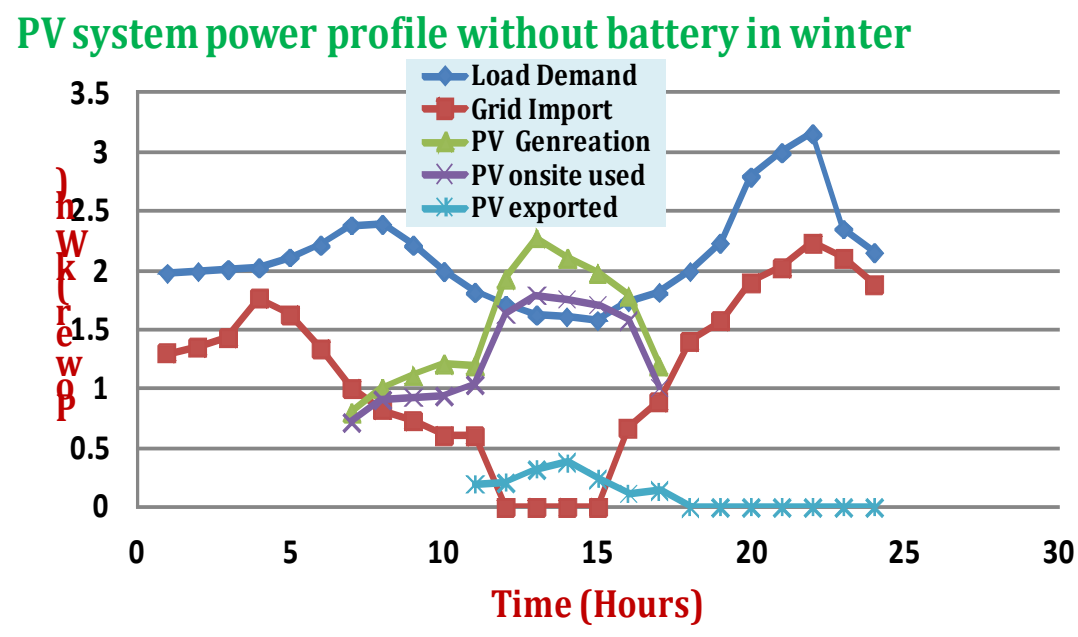

Figure 5. Power profiles of the PV system without battery storage system in winter.

In summer, the potential solar irradiance will be at its maximum intensity while electric grid requirements can be low but overall load demand can be increased due to high temperature. The results of power profile without BSS in summer are shown in Figure 6.

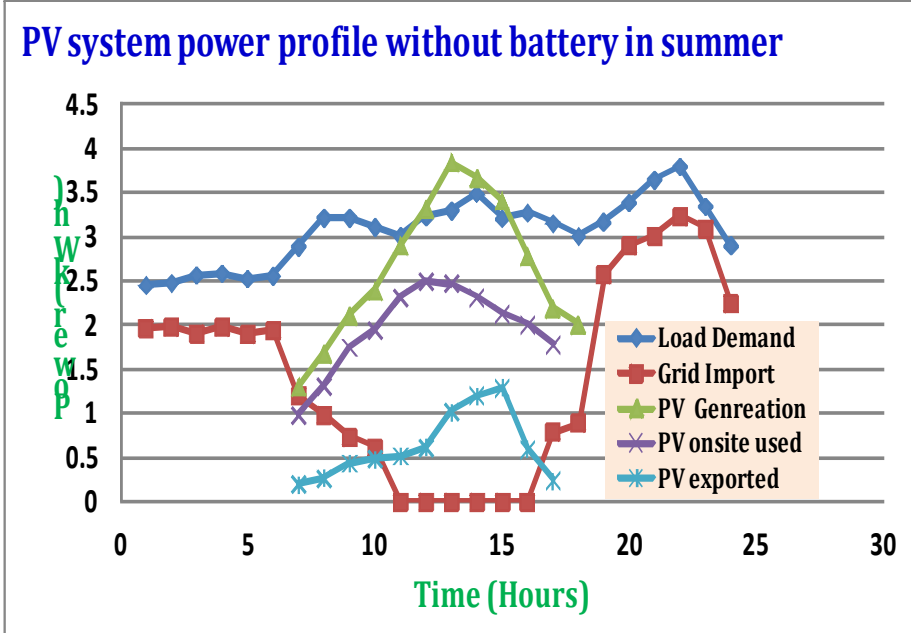

Figure 6. Power profiles of the PV system without battery storage system in summer. 
The results confirm that there is a significant PV generation especially at mid of the day and reaches to its peak at $13^{\text {th }}$ hour of the day. During PV generation periods, the grid electricity import is zero as PV power is more than onsite requirement and can be exported to the utility. But as there is no BSS installed, so the excess PV power is sold to the utility grid at low export tariffs.

\subsection{CASE SCENARIO 2: PV SYSTEM UNDER FIT SCHEME WITH BSS AT TOU TARIFFS}

This case scenario a PV system configuration is designed with BSS with FiT scheme by using ToU tariffs. The system configuration is shown in Figure 7.

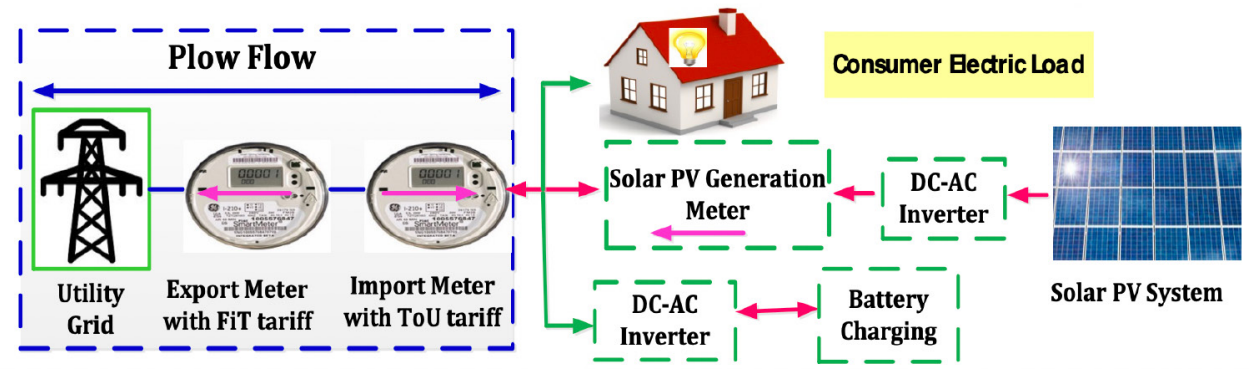

Figure 7. PV system design configuration with BSS under FiT and ToU Tariffs.

Figure 8 shows the results of PV system power profiles under FiT scheme and ToU tariffs on a selected day of winter. Load demand of the selected home is considered same as presented in Figure 5.

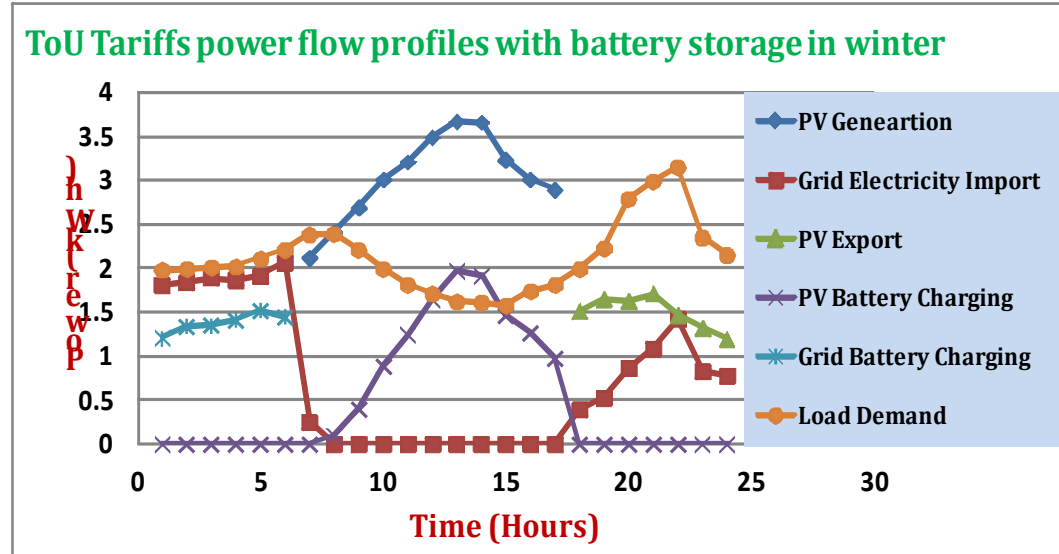

Figure 8. ToU tariff power profiles in winter. 
Considering the ToU tariffs presented in Figure 2, during low ToU tariff periods (between 1:00 to 6:00 hours), the maximum electricity is purchased from the utility grid and at the same time BBSS is also charged from the utility grid. Similarity during maximum PV irradiation periods, BBSS is charged from solar PV (between 8:00 to 17:00 hours). This BBSS from the both grid charging and PV charging is utilized optimally when ToU tariffs are high (between 17:00 to 24:00 hours). On the contrary, the selected day power profiles of winter are shown in Figure 9 Load demand of the selected home is considered same as presented in Figure 6.

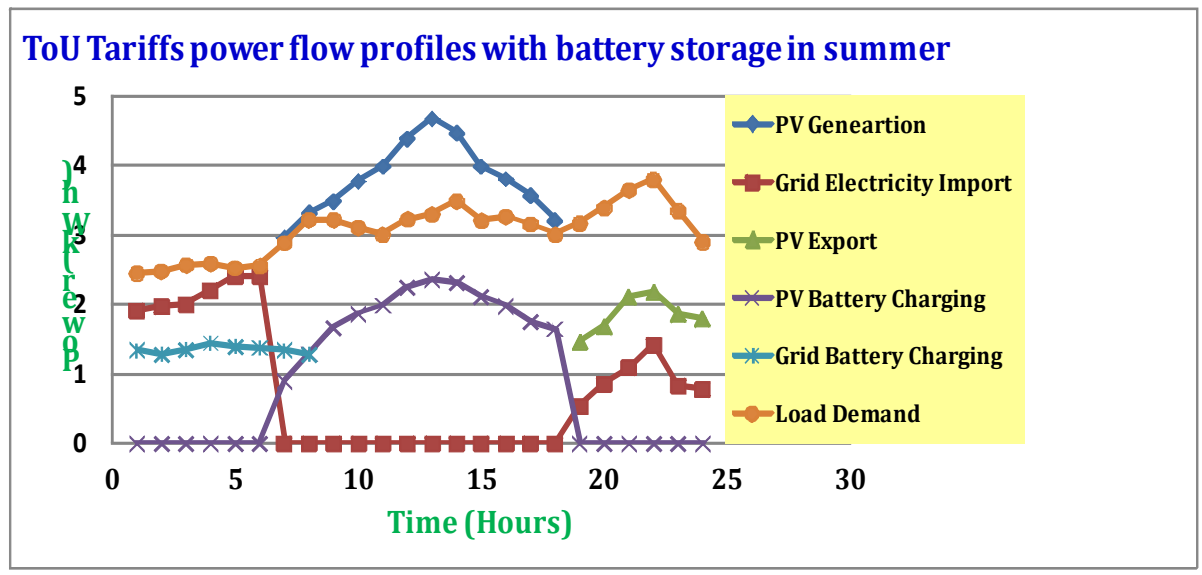

Figure 9. ToU tariff power profiles in winter.

Since in summer the generation from solar PV is significantly higher than the load demand, so battery charging either from PV or from utility grid is not required in typical PV generation hours (between 6:00 to 19:00) and after meeting own load requirements the excessive PV generation is exported to the utility grid at the low FiT export tariffs. This confirms that in summer the battery charging requirement is significantly low than in winter, whereas the required battery charging for usage of hours when no PV generation is available on site (between 19:00 to 6:00 hours), either low ToU tariffs or optimal FiT tariffs can be opted. 


\section{CONCLUSION}

The main objective of this research work is to propose an optimal balancing and control of dynamic load demand in a grid connected hybrid system using PV system with and without battery backup storage system. For this purpose two different PV system configuration were designed, modeled and evaluated for different case studies. In first scenario, PV system without BBSS under FiT scheme with flat tariffs was investigated for a typical day of winter and summer. In second scenario, PV system with BBSS under FiT scheme with ToU tariffs was investigated again for a typical day of winter and summer. After detailed analysis of case scenario's it was concluded a significant economy can be saved and optimal balancing and control can be achieved when PV system is configured with BBSS under FiT scheme by utilizing ToU tariffs.

\section{ACKNOWLEDGMENTS}

Authors are grateful to Mehran University of Engineering and Technology, Jamshoro, Pakistan, for the providing the necessary support, laboratory facilities and comfortable research environment. 


\section{REFERENCES}

Ahmed, N., Levorato, M. \& Li, G. P. (2018). Residential consumer-centric demand side management. IEEE Transactions on Smart Grid, 9(5), pp. 45134524. doi: http://dx.doi.org/10.1109/TSG.2017.2661991

Bakhshi, R. \& Sadeh, J. (2018). Economic evaluation of grid-connected photovoltaic systems viability under a new dynamic feed-in tariff scheme: A case study in Iran. Renewable energy, 119, pp. 354-364. doi: http://dx.doi. org/10.1016/j.renene.2017.11.093

Halepoto, I. A., Uqaili, M. A. \& Chowdhry, B. S. (2014). Least square regression based integrated multi-parametric demand modeling for short term load forecasting. Mehran University Research Fournal of Engineering and Technology, 33(2), pp. 215-226.

Ju, G., Wang, P., Goel, L. \& Xu, Y. (2018). A two-layer energy management system for microgrids with hybrid energy storage considering degradation costs. IEEE Transactions on Smart Grid, 9(6), pp. 6047-6057. doi: http://dx.doi. org/10.1109/TSG.2017.2703126

Kaplan, Y. A., Agalar, S. \& Bildircin, H. (2019). General situation of wind energy source in Turkey and wind turbine technologies. International Journal of Renewable Energy Technology, 10(1-2), pp. 56-67. doi: http://dx.doi. org/10.1504/IJRET.2019.097004

Narula, K. (2019). Global Energy System and Sustainable Energy Security. In The Maritime Dimension of Sustainable Energy Security (pp. 23-49). Springer, Singapore.

Sahito, A. A., Arain, M. A., Halepoto, I. A., Soomro, M. A. \& Jumani, M. J. (2016). Analyzing the Impacts of Wind Generation on Distribution System Performance. Indian Fournal of Science and Technology, 9, 47. doi: http://dx.doi. org/10.17485/ijst/2016/v9i47/108653 
Sahito, A. A., Halepoto, I. A., Uqaili, M. A., Memon, Z. A., Larik, A. S. \& Mahar, M. A. (2015). Analyzing the impacts of distributed generation integration on distribution network: A corridor towards smart grid implementation in Pakistan. Wireless Personal Communications, 85(2), pp. 545563. doi: http://dx.doi.org/10.1007/s11277-015-2754-y 